\title{
FOTOGRAFIAS E PESQUISAS HISTÓRICO-EDUCACIONAIS NO CENTRO- OESTE DO BRASIL: ANÁLISE DAS PRODUÇÕES SOCIALIZADAS NOS ENCONTROS DE HISTÓRIA DA EDUCAÇÃO DO CENTRO-OESTE (EHECO) 2011-2017
}

\author{
Photographs and historical-educational research in Central-West of Brazil: analysis of \\ socialized productions in the Meetings of History of Education of the Central-West \\ (EHECO) 2011-2017
}

Fotografías y investigaciones histórico-educacionales en el Centro-Oeste de Brasil: análisis de las producciones socializadas en los Encuentros De Historia de la Educación del Centro-Oeste (EHECO) 2011-2017

Maria Eduarda Ferro ${ }^{1}$

\begin{abstract}
Resumo
O presente artigo passa em revista as comunicações realizadas nas quatro edições do Encontro de História da Educação do Centro-Oeste - EHECO (2011-2017) com vistas a problematizar as menções e o emprego da fotografia nas pesquisas em História da Educação desenvolvidas nesta região. A metodologia empregada consistiu em realizar um levantamento quantitativo e uma análise qualitativa dos trabalhos completos presentes nos anais deste encontro científico que fizeram menção à fotografia enquanto fonte e/ou objeto de pesquisa. Como resultado deste exercício de análise apresenta-se uma categorização e uma contextualização das menções à fotografia presentes nestas produções, de acordo com o uso (ou desuso) deste artefato cultural.
\end{abstract}

PALAVRAS-CHAVE: Imagem. Foto. Fonte. Objeto

\begin{abstract}
This article reviews the communications presented in the four editions of the Meeting of History of Education of the Central-West - EHECO (2011-2017) in order to problematize the mentions and the use of photography in the researches in History of Education developed in this region. The methodology employed was to perform a quantitative survey and a qualitative analysis of the complete papers present in the annals of this scientific meeting that made mention of photography as a source and / or object of research. As a result of this exercise of analysis, a categorization and contextualization of the mentions of photography present in these productions is presented, according to the use (or disuse) of this cultural artefact.
\end{abstract}

KEYWORDS: Image. Photo. Source. Object

\footnotetext{
${ }^{1}$ Docente - Universidade Estadual de Mato Grosso do Sul - Curso de Pedagogia. Mestre em Educação. Endereço: Rod. Dourados-Itahum, km 12 - Cidade Universitária - Dourados - MS - CEP 79804-970 - Telefone: (67) 3902-2681. E-mail: mariaeduardaferro@hotmail.com
} 


\section{Resumen}

Este artículo revisa las comunicaciones presentadas en las cuatro ediciones del Encuentro de Historia de la Educación del Centro-Oeste - EHECO (2011-2017) con el fin de problematizar las menciones y el uso de la fotografía en las investigaciones en Historia de la Educación desarrolladas en esta región. La metodología empleada fue realizar una encuesta cuantitativa y un análisis cualitativo de los artículos completos presentes en los anales de esta reunión científica que hizo mención de la fotografía como fuente y / o objeto de investigación. Como resultado de este ejercicio de análisis, se presenta una categorización y contextualización de las menciones de la fotografía presente en estas producciones, de acuerdo con el uso (o desuso) de este artefacto cultural.

PALABRAS CLAVE: Imagen. Foto. Fuente. Objeto.

\section{INTRODUÇÃO}

Alinhada à proposição do dossiê nominado "Impressos e fontes para a História da Educação no Centro-Oeste do Brasil" o presente artigo objetiva lançar reflexões acerca do emprego da fotografia como documento e/ou objeto de pesquisas na área da História da Educação no Centro-Oeste brasileiro. Para tanto, apresenta o percurso e algumas reflexões provenientes de um exercício de análise historiográfica acerca da presença da fotografia nas comunicações socializadas nas quatro edições do Encontro de História da Educação do Centro-Oeste - EHECO (2011-2017).

A fotografia tem sido efetivamente utilizada como fonte e/ou objeto de pesquisa nas investigações histórico-educacionais produzidas na região Centro-Oeste? Ou será que a imagem fotográfica passou a ser mais frequentemente mencionada como parte do corpus documental localizado ou até mesmo eleito para dada investigação, sem que tal artefato seja necessariamente mobilizado? E, ainda, quando empregadas imagens fotográficas na produção do conhecimento histórico educacional, quais têm sido as principais escolhas no que tange às interlocuções teórico-metodológicas em jogo? Que reflexões sobre o ofício do historiador da educação podem ser empreendidas com um exame mais detido destas produções? Tais questões mobilizaram e nortearam este exercício analítico e o presente texto visa a sua exposição.

A estrutura do artigo intenciona apresentar considerações acerca de decisões tomadas e do caminho percorrido para a realização do exercício analítico, apresentar dados quantitativos sobre os trabalhos que fazem menção à fotografia e expor uma análise qualitativa de seu conteúdo.

\section{As escolhas e o percurso: a paisagem e o ajuste do foco}


Quanto às escolhas realizadas no percurso deste exercício, convêm fazer alguns registros. A eleição das produções socializadas no EHECO como corpus documental privilegiado de análise se deu em decorrência de alguns fatores, dentre os quais se destacam os propósitos que nortearam a criação deste encontro científico, qual seja: socializar estudos e pesquisas produzidos na vasta região composta pelos estados de Goiás, Mato Grosso, Mato Grosso do Sul e o Distrito Federal, caracterizados por semelhanças e diferenças provenientes das suas respectivas formações históricas (SÁ; FURTADO; HONÓRIO FILHO, 2016). Soma-se a esse fator o reconhecimento e a legitimidade conquistada pelo EHECO junto à entidade científica nacional da área, a Sociedade Brasileira de História da Educação (SBHE), como fórum privilegiado de socialização e debate da produção da região.

Vale registrar, ainda, que a escolha por fazer esse levantamento das produções a partir dos anais do EHECO também se deve à especificidade das perguntas que nortearam este exercício. Ao serem examinadas comunicações socializadas em evento, em detrimento de artigos publicados em periódicos, é possível perscrutar o movimento de produção científica da área na sua dinamicidade. Estes, diferentemente dos periódicos, mais seletivos e institucionalmente formatados a determinados escopos editoriais, abarcam pesquisas em estados de produção distintos, como projetos e intenções de pesquisa, estudos em andamento e resultados de investigações concluídas.

A particularidade de propor um balanço centrado no inquérito sobre o emprego do artefato fotografia na condição de fonte e na condição de objeto de pesquisa impôs algumas decisões metodológicas que tornaram complexo o levantamento do corpus documental deste exercício. O primeiro passo consistiu em fazer a varredura dos trabalhos completos presentes nas quatro edições do EHECO (2011-2017) em busca da totalidade de comunicações que apresentassem retorno positivo para o termo "foto". Para tanto, foi feito uso da ferramenta de busca disponibilizada pelos leitores de documentos em formato pdf. A escolha do radical "foto", e não da palavra "fotografia", justifica-se pela precaução em contemplar palavras derivadas deste termo a exemplo de "fotográfico(a)" e "fotógrafo(a)", que não retornariam caso fosse feita a busca exclusivamente pela palavra "fotografia" .

\section{A fotografia do campo: os achados}

\footnotetext{
${ }^{2}$ A mesma metodologia foi desenvolvida para realização do balanço referente às quatro primeiras edições do Congresso Brasileiro de História da Educação (CBHE) em FERRO (2017).
} 
Nesse primeiro levantamento, apurou-se que o termo "foto" esteve presente em 28 trabalhos completos apresentados à primeira edição do evento, e, respectivamente, em 33, 27 e 21 trabalhos completos apresentados às edições subsequentes. Logo, 109 comunicações ao longo das 4 edições do evento fizeram menção a fotografia em algum ponto dos textos dos trabalhos completos presentes nos anais das 4 primeiras edições do evento (Tabela 1)

TABELA 1. Presença e distribuição de menções à fotografia nos trabalhos completos.

\begin{tabular}{|c|c|c|c|c|c|}
\hline $\begin{array}{c}\text { EDIÇÃOO } \\
\text { DO } \\
\text { EVENTO }\end{array}$ & $\begin{array}{c}\text { TRABALHOS } \\
\text { COMPLETOS } \\
\text { NOS ANAIS }\end{array}$ & $\begin{array}{c}\text { TRABALHOS } \\
\text { COM } \\
\text { MENÇÃO À } \\
\text { FOTOGRAFIA }\end{array}$ & $\begin{array}{c}\text { TRABALHOS } \\
\text { COM } \\
\text { MENÇÃO } \\
\text { ÚNICA }\end{array}$ & $\begin{array}{c}\text { TRABALHOS } \\
\text { COM } 2 \text { A } 5 \\
\text { MENÇÖES }\end{array}$ & $\begin{array}{c}\text { TRABALHOS } \\
\text { COM } 6 \text { OU } \\
\text { MAIS } \\
\text { MENÇÕES }\end{array}$ \\
\hline $\begin{array}{c}\text { I EHECO } \\
2011\end{array}$ & 110 & 28 & 16 & 09 & 03 \\
\hline $\begin{array}{c}\text { II EHECO } \\
2013\end{array}$ & 130 & 33 & 12 & 18 & 03 \\
\hline $\begin{array}{c}\text { III EHECO } \\
2015\end{array}$ & 104 & 27 & 14 & 10 & 03 \\
\hline $\begin{array}{l}\text { IV EHECO } \\
2017\end{array}$ & 113 & 21 & 06 & 11 & 04 \\
\hline TOTAIS & 457 & 109 & 48 & 48 & 13 \\
\hline
\end{tabular}

Fonte: Elaborada a partir do exame das comunicações presentes nos anais dos EHECO (2011-2017), disponíveis em htpp://eheco.com.br/ até 21/03/18.

Sobre esses números é válido dizer que apesar da ligeira oscilação no total de trabalhos apresentados às diferentes edições do $\operatorname{EHECO~(110,~130,~} 104$ e 114), as três primeiras mantiveram um percentual estável de trabalhos com menções, que girou em torno de $25,5 \%$ a $26 \%$. Na última edição, realizada no ano de 2017, observou-se um ligeiro decréscimo nessa cifra, que caiu para 18,5\%. Apesar dessa oscilação tênue, é possível afirmar que o quantitativo de trabalhos completos que mencionaram o termo "foto" permaneceu praticamente estável.

Para além de uma tomada panorâmica sobre os números absolutos, é importante ajustar o foco de análise, conforme a tabela organizada acima sugere. Apesar de haver um número significativo de trabalhos, em cada edição do evento, que se reporta à fotografia, uma análise mais detida sobre o conteúdo de tais trabalhos e sobre o contexto em que as menções a esse artefato ocorrem indica que os números absolutos podem induzir a conclusões equivocadas sobre o efetivo emprego da documentação fotográfica nas pesquisas em história da educação da região.

Se, num primeiro momento o quantitativo de 109 trabalhos pode sugerir que as imagens fotográficas têm sido frequentemente empregadas nas produções, um olhar mais detido sobre o conteúdo dos trabalhos completos aponta que uma boa fração deste montante 
(44\%) fez menção ao termo "foto" uma única vez e a maior parcela deste mesmo montante (88\%) não excedeu a cinco menções. A apresentação destes dados quantitativos não se constitui preciosismo numérico. Antes, intenta apontar que o fenômeno numérico, aqui reconhecido como a totalidade de trabalhos que faz menção ao termo "foto" e seus derivados, deve ser considerado com cautela.

Decidiu-se por inquerir de forma mais detida àqueles que mencionavam a fotografia de forma mais recorrente. Estabeleceu-se, então, um conjunto menor de trabalhos, na totalidade de 13, definidos a partir do retorno ao termo fotografia no quantitativo de seis ou mais ocorrências. Adotou-se um protocolo de questões para tais trabalhos que permitiu o estabelecimento de algumas inferências acerca do uso ou desuso da fotografia nas pesquisas em história da educação publicizadas no encontro da área, regional Centro-Oeste.

Foram identificados, portanto, dois conjuntos de comunicações, um primeiro e mais volumoso que fez menções esporádicas ao termo foto e seus derivados no corpo do texto completo e um segundo, bem mais restrito numericamente, que fez menções regulares à fotografia. Numericamente, definiu-se como comunicação com menções esporádicas aqueles textos cuja ocorrência do termo foto e seus derivados se deu em até cinco vezes no corpo do texto completo e por menções regulares os textos que apresentaram ocorrência igual ou superior a seis. Via de regra, os textos submetidos aos anais do EHECO possuem em média oito a dez laudas, entretanto há trabalhos com até 16 laudas. A seguir são feitas algumas explanações sobre o agrupamento de trabalhos com menções esporádicas à fotografia e, a seguir, sobre o agrupamento de trabalhos que fazem menções recorrentes ao radical foto e seus derivados.

\section{Menções Esporádicas e os seus contextos de ocorrência}

Este primeiro conjunto de trabalhos atinge a cifra de $88 \%$ do total de comunicações que fazem menção à fotografia. Observou-se que as referências ao radical foto e seus derivados ocorrem em circunstâncias nominadas como menções de caráter casual; menções de legitimação documental e menções descritivas / narrativas, explanadas a seguir.

Nominou-se como menções de caráter casual aquelas referências ao termo foto e seus derivados que ocorrerem num contexto desprendido da concepção de fotografia como fonte ou objeto de pesquisa. Exemplificando, Vasconcelos (2013), ao apresentar a proposta do Museu da Educação do Distrito Federal, dedicado à memória da Educação de Brasília, dispõe: "A imagem caricata do brasileiro influenciou sua autoestima nacional refletida numa nacionalidade deturpada da realidade caricata de um 
indivíduo sugerido nos estúdios de Walt Disney. A legião não era a "Urbana", era dos "Zé Cariocas", de listras horizontais e falar matraqueado. Sobre estes ícones, o povo brasileiro desenvolveu uma memória social primitiva, inspirada na crítica e no riso do atraso predominante, e nos suspiros da beleza natural de suas mulheres, retratando uma fotografia ${ }^{3}$ engessada do país continental, sem positivo ou negativo, apenas esvaziada de sentido". (p. 02)

Neste contexto destacado acima a palavra fotografia encontra-se evidentemente empregada no sentido figurado, reportando-se à difusão de uma determinada imagem estereotipada de nação. Outro exemplo de menção considerada de caráter casual é encontrado em Scudder e Monteiro (2011), que trouxeram para o corpo do texto a citação da fala da narrativa de uma entrevistada “(...) Aí Priscila, meu pai nunca teve infância, só viveu preso, eu não tenho uma foto ${ }^{4}$ do meu pai, só lembro o rosto dele de cabeça" (p. 05). Bem como em França, Issa e Silva (2015), que incorporaram ao corpo do texto um trecho poético no qual o radical foto acha-se presente "Um porta-retrato / Uma foto ${ }^{5}$ permanente / Figura jovem e atraente / A imagem retrata (...)" (p. 13).

Em síntese, nos exemplos mencionados acima, e em outros, considerados menções de caráter casual, a fotografia não é apreendida como fonte e/ou objeto de pesquisas histórico educacionais, pois o radical foto figura no corpo do texto de forma episódica. É válido registrar que as múltiplas menções ao termo foto e seus derivados foram analisadas uma a uma no corpo dos textos completos de modo que em alguns casos um mesmo trabalho apresentou menções de caráter distinto. Isto significa dizer que o esforço de análise dos trabalhos não objetivou o estabelecimento de um sistema rígido de classificação com vistas a qualificá-los em si como pertencentes a uma ou outra suposta categoria estanque. O exercício analítico objetivou identificar as ocorrências das referências (por vezes variadas) ao radical foto e seus derivados para, sobretudo, ponderar de que modo os contextos de tais menções nos apontam aspectos relevantes acerca da produção da pesquisa em história da educação na região Centro-Oeste.

No caso do primeiro trabalho mencionado acima, mais adiante, a autora faz menção novamente à fotografia, desta vez referindo-se ao artefato como parte do acervo do Museu da Escola, criado a partir do Centro de Memória da Educação da UFMG, ou seja, neste trecho,

\footnotetext{
${ }^{3}$ Destaque inserido.

${ }^{4}$ Destaque inserido.

${ }^{5}$ Destaque inserido.
} 
reproduzido textualmente abaixo, a menção à fotografia se dá um contexto de legitimação deste artefato como tipologia documental.

(...) o Museu busca retratar a história da educação do Estado através da materialidade, mostrando o trabalho cotidiano do professor exemplificado na figura de professores homenageados por seu valor educacional. As salas de aulas estão reproduzidas de forma fiel de acordo com as estruturas da época e dos materiais escolares que testemunham a prática pedagógica e da experiência a partir dos meios de inserção da criança no mundo social. Estão expostas fotografias ${ }^{\mathbf{6}}$, carteiras escolares de diversas décadas, diplomas, lousas, canetas, lápis, tinteiros, cartilhas de alfabetização, cartazes, livros infantis, livros de leitura, cadernos, cadernos de caligrafia, ábaco, jogos pedagógicos, pastas escolares, merendeiras, cartazes de ensino, globos, mimeógrafos, projetores de filmes, boletins, cadernetas escolares, móveis e piano e outros materiais (VASCONCELOS, 2013, p.08).

Como o próprio termo indica, as menções de legitimação documental têm por característica o emprego do radical foto e seus derivados em contextos de validação do artefato fotografia em seu caráter documental, como fonte de pesquisa, o que as difere das menções de caráter casual. Como no excerto acima, foram localizadas numerosas ocorrências de referência à fotografia no contexto nominado como menções de legitimação documental. Seguramente essa espécie de chamada à fotografia foi a mais frequentemente encontrada dentre os 109 trabalhos presentes nas quatro edições do EHECO que fizeram algum tipo de referência a este artefato.

As menções de legitimação documental estiveram presentes em circunstâncias como o anúncio da adesão a uma determinada orientação teórica, especialmente quando se explana acerca da revolução documental operada pela nova história cultural, como fizeram Santos, Leite e Viana (2015),

"Apontamos, contudo, que com a renovação da 'Nova História' e a consolidação do campo da história da educação no Brasil, uma série de temas e pesquisas vem demandando um operar historiográfico que compreenda outras fontes - como fotografias ${ }^{7}$, relatos de viajantes, literatura, imprensa pedagógica, etc.” (p.5).

O excerto acima não faz menção à orientação de nenhum teórico específico, mas é válido destacar a presença recorrente de citações literais ou indiretas dos franceses Jacques Le Goff (1992) e Marc Bloch (2002) (em menor incidência), cujas produções em muito

\footnotetext{
${ }^{6}$ Destaque inserido.

${ }^{7}$ Destaque inserido.
} 
contribuíram para a difusão, no Brasil, das ideias consonantes ao movimento do alargamento das fontes.

Outro tipo de ocorrência de menção de legitimação documental pode ser observada em trabalhos que arrolam a fotografia em um quadro descritivo da tipologia documental disponível no acervo de uma determinada instituição, objeto do estudo do em questão, como observado em Santini (2011), que alerta para a potencialidade de uso dessa documentação, "Documento: Fotografias / Possibilidades de Pesquisa: Permite apreender a riqueza dos espaços, dos ambientes, dos objetos e das pessoas" (p.05). São numerosos os trabalhos que evocam a fotografia como fonte documental localizada durante os procedimentos de levantamento das fontes da investigação em curso, sem, entretanto, operar com essa tipologia documental ao logo do texto em questão.

Ainda neste agrupamento de comunicações com baixa incidência de retorno ao radical foto, foram identificadas circunstâncias em que são feitas referências à fotografia nominadas como menções descritivas / narrativas.

Foram agrupadas na categoria menções descritivas / narrativas as referências à imagem fotográfica que se caracterizaram por legitimar a imagem fotográfica como documentação viável para a produção do conhecimento histórico, mas que no corpo do texto (no caso, da comunicação submetida ao evento), ainda que os pesquisadores não as tenham ignorado, não tiveram a pretensão de aprofundar na sua análise. Neste contexto, o emprego da fotografia se deu de modo ilustrativo; seu uso é feito, frequentemente, como expressão de uma realidade, como testemunha ocular de algo que tenha acontecido no passado, sem que se opere uma problematização sobre o contexto de produção desta documentação.

Em comunicação que versa sobre a participação militar no processo de escolarização na faixa de fronteira do Brasil com o Paraguai, Souza (2011), apresenta uma fotografia de um agrupamento de crianças e assim descreve "Na fotografia" percebe-se a existência de cerca de quarenta alunos, meninos e meninas, de idades diversas, grupados por sexo (meninos à direita e meninas à esquerda)". (SOUZA, 2011, p. 05). Movimento similar é observado no texto de Amorim e Ferreira (2013, p. 09), que insere a imagem fotográfica no corpo do texto e atesta "A foto ${ }^{10}$ abaixo retrata presença das alunas para realização dos cursos oferecidos pelo CTMCuiabá".

\footnotetext{
${ }^{8}$ Destaque inserido.

${ }^{9}$ Destaque inserido.

${ }^{10}$ Destaque inserido.
} 
Importa dizer que nestes casos pinçados como exemplos e nos demais que foram categorizados como descritivos / narrativos, a fotografia é tomada como um documento trazido para o corpo do texto a fim de ilustrar, referendar, corroborar uma argumentação em curso. Não há um movimento sistemático de problematização desta documentação, nas suas especificidades, como acautelam os referenciais teóricos que dispõem sobre o estatuto documental deste artefato cultural.

\section{Menções regulares e seus contextos de ocorrência}

Dentre o conjunto de 109 trabalhos que fizeram menção à fotografia, menos de $12 \%$ o fez em número de seis ou mais vezes, sendo, portanto, nominados como comunicações com menções regulares. Inicialmente, supôs-se que a análise dos textos com maior incidência de menções à fotografia desse a conhecer outros contextos de chamada, distintos dos já delineados acima - esporádicos; de legitimação documental e descritivos / narrativos -, que fossem localizadas comunicações em que este artefato cultural tivesse sido eleito como objeto de pesquisa, a exemplo do ocorrido em exercício desta mesma natureza realizado com o corpus documental das quatro primeiras edições do CBHE. Entretanto, por vezes a pesquisa conduz a resultados diferentes das hipóteses de partida do pesquisador e, nesta oportunidade, não foi diferente. As menções localizadas continuaram a repetir os padrões de chamada já delineados anteriormente.

Um olhar panorâmico sobre esse agrupamento de textos indicou que o conjunto é composto, grosso modo, por comunicações que apresentaram de forma recorrente, três intencionalidades. Foi identificado um subconjunto de trabalhos cujo objetivo consistiu em apresentar resultados parciais ou finais de pesquisa, no qual a fotografia figurou como fonte complementar. Um segundo subconjunto delineado caracteriza-se por comunicações que visaram trazer para o debate projetos ou intenções de pesquisa, por vezes em processo de ajuste, nos quais a fotografia é elencada como provável fonte a ser empregada futuramente. E, por fim, um terceiro subconjunto de comunicações que socializa experiências de localização ou tratamento de acervos específicos (não exclusivamente de vocação imagética).

Para além dessas considerações, julgou-se oportuno um exame mais detido destes trabalhos. Deste modo, as comunicações foram inquiridas em alguns aspectos específicos como (i) o nível de formação de seus autores; (ii) o vínculo institucional dessas produções; (iii) a temática da comunicação; (iv) o recorte temporal da pesquisa; (v) a natureza do acervo fotográfico em questão e (vi) os referenciais teóricos mobilizados, especialmente em relação a documentação fotográfica. 
Quanto à primeira questão, constatou-se, neste conjunto de 13 trabalhos, a presença de autoras ${ }^{11}$ com níveis de formação acadêmica diversa, de estudantes de iniciação científica a pesquisadoras experientes como professoras doutoras atuantes como docentes de programas de pós-graduação da região Centro-Oeste. A formação inicial destas autoras também se mostrou bastante diversificada. Pedagogas e historiadoras figuraram em condições equilibradas de representatividade, seguidas, em menor número por licenciadas em artes, matemática e bacharéis em psicologia e direito. A formação em nível de mestrado se manteve equilibrada entre autoras oriundas de programas de pós-graduação em Educação e programas de pós-graduação em História, entretanto, o registro da formação em nível de doutorado em Educação apresentou-se maior que o doutorado em História.

Um aspecto a ser registrado sobre o vínculo institucional das produções é o fato da totalidade de trabalhos que compõem este agrupamento serem oriundos de instituições públicas de ensino superior, sejam estas federais ou estaduais. Sete diferentes instituições acharam-se representadas neste agrupamento, sendo a Universidade Federal da Grande Dourados (UFGD), a Universidade Federal de Mato Grosso (UFMT), a Universidade Estadual de Mato Grosso do Sul (UEMS) e a Universidade Federal de Goiás (UFG-Catalão) as mais frequentemente representadas em número de trabalhos e, consequentemente, de autoras $^{12}$.

Sobre essa representatividade, convêm ponderar que as instituições mencionadas foram os espaços acadêmicos que sediaram a quatro edições do EHECO e são as instituições que apresentam em seus respectivos programas de pós-graduação em Educação, linha de pesquisa que faz menção específica à palavra História, conforme apurado por Xavier (2016, p.05).

Ainda sobre a autoria dessas comunicações, apesar de haver sete instituições distintas representadas nos 13 trabalhos em tela, apenas dois deles são assinados por parcerias interinstitucionais, sendo um deles por autoras de um mesmo estado e o outro por autoras de estados vizinhos. Esse dado, referente à baixa produção em condições de parcerias interinstitucionais, foi apontado em balanço recente realizado por Pessanha (2016), para a qual “(...) as perspectivas para um intercâmbio regional em pesquisa e escrita em História da

\footnotetext{
${ }^{11} \mathrm{~A}$ autoria dos textos que compõem esse agrupamento de trabalhos é assinada por 17 mulheres e quatro homens, motivo pelo qual se optou pelo emprego do tratamento nominal no gênero feminino.

${ }^{12}$ Além das quatro instituições já nomeadas também foi registrada uma produção com vínculo institucional da Universidade de Brasília (UNB); uma da Universidade do Estado de Mato Grosso (UNEMAT) e uma da Universidade Federal de Uberlândia (UFU).
} 
Educação no Centro-Oeste são promissoras e favoráveis. Falta, ainda, intensificar e ampliar de forma sistêmica as parcerias em projetos de pesquisa e em publicações” (p. 44).

As temáticas de estudo identificadas dentre essas comunicações que fizeram referência à fotografia foram predominantemente os estudos de instituições escolares e de práticas pedagógicas ao lado das comunicações que visaram socializar experiências sobre o levantamento de fontes e a organização de acervos. De certa forma o comportamento das temáticas no interior deste agrupamento demonstrou-se similar à distribuição dos interesses de pesquisa averiguada por Sá, Furtado e Honório Filho (2016), que apuraram a predominância, nas três primeiras edições do EHECO, das pesquisas sobre instituições escolares, suas culturas e práticas, seguida pelo eixo "Fontes, categorias e métodos de pesquisa em História da Educação". A fotografia também foi arrolada como documento, porém menos vezes, em comunicações que tiveram como temática estudos de gênero, pesquisa autobiográfica, ensino primário rural e educação patrimonial.

Quanto ao recorte temporal dessas comunicações que fizeram referência à documentação fotográfica de modo mais recorrente, é possível afirmar a predominância de uma janela temporal que se inicia na segunda metade do século XX e segue até a primeira década dos anos 2000, ou seja, o tempo presente. A natureza dos acervos mencionados nas comunicações é predominantemente de caráter escolar, com ênfase a imagens de instituições públicas de ensino. Dentre as 13 comunicações, apenas três fizeram referência à documentação fotográfica não escolar na pesquisa em história da educação. Registra-se em Erbs (2017), menção à possibilidade de imagens fotográficas de caráter privado serem fontes potenciais para pesquisas de história de vida e narrativas auto-biográficas e, em Debona (2013) e Marques (2011), a mobilização de acervo imagético (não exclusivamente fotográfico) de livros didáticos de História para a análise da categoria gênero. As três comunicações mencionadas não empregaram, no corpo do texto, fotografias em suas análises.

É igualmente escasso o número de trabalhos deste agrupamento que apresenta resultados de pesquisa e faz menção a referenciais teóricos de análise da fotografia, nas suas múltiplas especificidades. Apenas três, dentre as 13 comunicações, que reúnem essas condições, os apontam ${ }^{13}$. Grativol e Ferreira (2017), ao avaliarem as práticas pedagógicas e as concepções de infância presentes em uma instituição de educação infantil, estabeleceram um

\footnotetext{
${ }^{13}$ Registre-se que nesta contagem foi excetuada uma comunicação que anunciou dentre suas referências duas obras clássicas A câmara clara: nota sobre a fotografia, de Roland Barthes e Magia e técnica, arte e política: ensaios sobre literatura e história da cultura, de Walter Benjamin. A opção se justifica pelas menções às referidas obras terem encontrado lugar exclusivamente na seção "referências" e, sobretudo, pelo fato da comunicação consistir em projeto ou intenção de pesquisa, o que não permite nenhum tipo de análise sobre a apropriação do seu conteúdo.
} 
diálogo com as proposições de Boris Kossoy (1989). Diálogo este, parcial, conforme alertado pelas autoras, "Para analisar as fotografias neste trabalho, faremos uso da análise iconográfica, indicada por Kossoy (1989), porém ela será abordada somente em relação ao conteúdo fotográfico, ou seja, o "assunto da fotografia" que registra os aspectos internos da instituição" (p. 04). Silva, Leão e Camargo (2013) ao se disporem a discutir fundamentos teóricos para interpretação de diversas tipologias documentais, dentre elas, imagens fotográficas, fazem referência ao mesmo autor e obra. E, por fim, Luiz e Santos (2011), que socializam uma experiência de projeto de intervenção junto à uma instituição de ensino, com vistas à constituição de acervo e organização de banco de dados, mencionaram referenciais clássico de discussão da imagem fotográfica, como Roland Barthes (1984); Walter Benjamin (1994) e Peter Burke (2004), bem como textos de autoria de pesquisadores brasileiros cujas contribuições repercutem a discussão sobre o emprego de imagens fotográfica na produção do conhecimento histórico, como Cardoso e Mauad (1997) ou Mauad (1996), e ainda, de pesquisadores cujas contribuições situam-se mais especificamente no terreno das produções em história da educação, como Bencostta $(2001)^{14}$.

Ainda sobre essas comunicações que fazem referência recorrente à fotografia e valemse de referenciais teóricos de análise desta tipologia documental, nota-se que elas estão esparsas nos eventos, tendo ocorrido uma em 2011, outra em 2013, e a terceira em 2017. A distribuição dispersa das comunicações, das autorias e vínculos institucionais não permite a localização de um ou mais grupos que estejam se dedicando ao estudo mais sistemático da fotografia como fonte/objeto de pesquisa, ou mesmo a recorrência de pesquisadores independentes que, no campo da pesquisa em história da educação do Centro-Oeste, estejam se dedicando à fotografia.

\section{CONSIDERAÇÕES FINAIS}

Sem negar os avanços registrados nos últimos anos na produção da área de história da educação na região Centro-Oeste, este exercício apontou para a necessidade de se adensar as análises de balanços quantitativos, de se examinar de modo mais detido qualitativamente o que e como tem se dado a escrita da história da educação nesta região, inclusive para poder identificar temáticas de importância regional que se encontram parcial ou completamente descobertas, bem como fontes com potencial documental inexploradas.

\footnotetext{
${ }^{14}$ Também foram mencionados, exclusivamente na seção referências, Souza (2001), Mauad (1990) e Leite (1998).
} 
É forçoso afirmar que apesar do discurso vigente acerca do alargamento das fontes, os documentos escritos permanecem ocupando lugar central na escrita da História da Educação. Esta análise, circunscrita à região Centro-Oeste do Brasil, sugere que essa centralidade da documentação textual não se deve ao questionamento da legitimidade ou do valor documental da imagem, visto que a fotografia é frequentemente afirmada como tal. O emprego ainda tímido das imagens fotográficas como fonte/objeto de pesquisa parece estar relacionado a fatores que envolvem questões de outra ordem.

O ofício dos historiadores da educação da região Centro-Oeste ainda se ressente da escassez de coleções fotográficas recolhidas e tratadas como documentação de arquivo pelos setores iconográficos (quando há) das instituições públicas de preservação da memória. Esse aspecto contribui para tornar ainda mais árduo o caminho a ser percorrido por aqueles historiadores que se dispõem a trabalhar nessa seara ${ }^{15}$. Ao que foi demonstrado, há iniciativas, dentre os grupos de pesquisas representados nas comunicações analisadas, na localização de acervos - especialmente de instituições educativas e de práticas de educação formal -, na sua catalogação e disponibilização com ferramenta de pesquisa, o que pode ser um aceno em relação a trabalhos futuros com a incorporação da fotografia.

\section{REFERÊNCIAS}

AMORIM, Rômulo Pinheiro de; FERREIRA, Márcia dos Santos. Professora Nazita Santiago: uma intelectual da educação em Mato Grosso (1960 - 1990). In: Anais do II Encontro de História da Educação do Centro-Oeste. Dourados (MS), 2013, p. [1-]-[12-].

BARTHES, Roland. A câmara clara: nota sobre a fotografia. Trad. Júlio Castañon Guimarães. Rio de Janeiro: Nova Fronteira, 1984.

BENCOSTTA, Marcus Levy Albino. Arquitetura e espaço escolar: reflexões acerca do processo de implantação dos primeiros grupos escolares de Curitiba (1903 - 1928). Educar, Curitiba, n. 18, p. 103 - 141, Jul. /dez. 2001.

BENJAMIN, Walter. Pequena história da fotografia. In: Obras Escolhidas: magia e técnica, arte e política. 7. ed., trad. Sérgio Paulo Rouanet, São Paulo, Brasiliense, 1994, p. 91-107.

BLOCH, Marc. Apologia da História ou o oficio do historiador. Rio de Janeiro: Jorge Zahar Editor, 2002.

BURKE, Peter. Testemunha ocular: história e imagem. Traduzido por Vera Maria Xavier dos Santos. Bauru (SP): EDUSC, 2004.

CARDOSO, Ciro Flamarion e MAUAD, Ana Maria. História e imagem: os exemplos da fotografia e do cinema. In: CARDOSO, Ciro Flamarion e VAINFAS, Ronaldo (org.)

\footnotetext{
${ }^{15}$ Esse aspecto não foi explorado neste texto, mas é oportuna uma reflexão mais detida sobre a existência e as condições de funcionamento dos setores iconográficos das principais instituições de preservação da memória da região Centro-Oeste.
} 
Domínios da História: ensaios de teoria e metodologia. Rio de Janeiro: Editora Campus, 1997, p. 401-417.

DEBONA, Jackson James. Relações de gênero e livro didático de história: uma abordagem possível? In: Anais do II Encontro de História da Educação do Centro-Oeste. Dourados (MS), 2013, p. [1-]-[12-].

ENCONTRO DE HISTÓRIA DA EDUCAÇÃO DO CENTRO-OESTE. 1, 2011, Cuiabá (MT). Anais. Disponível em: <http://eheco.com.br/index.php/ehecos-anteriores/>

ENCONTRO DE HISTÓRIA DA EDUCAÇÃO DO CENTRO-OESTE. 2, 2013, Dourados (MS). Anais. Disponível em: <http://eheco.com.br/index.php/ehecos-anteriores/>

ENCONTRO DE HISTÓRIA DA EDUCAÇÃO DO CENTRO-OESTE. 3, 2015, Catalão (GO). Anais. Disponível em: <http://eheco.com.br/index.php/ehecos-anteriores/>

ENCONTRO DE HISTÓRIA DA EDUCAÇÃO DO CENTRO-OESTE. 4, 2017, Campo Grande (MS). Anais. Disponível em: <http://eheco.com.br/index.php/ehecos-anteriores/>

ERBS, Rita Tatiana Cardoso. Os outros na narrativa: uma proposta de análise para os materiais coletados nas pesquisas com histórias de vida e narrativas (auto)biográficas. In: Anais do IV Encontro de História da Educação do Centro-Oeste. Campo Grande (MS), 2017, p. [1-]-[12-].

FERRO, Maria Eduarda. A presença da fotografia como fonte e objeto de pesquisa nos Congressos Brasileiros de História da Educação (2000-2006): apontamentos iniciais. Artigo apresentado à disciplina. Faculdade de Educação da Universidade de São Paulo, 2017.

FRANÇA, Patrícia de Souza Torres; ISSA, Sílvia Aparecida Caixeta; SILVA, Rubislei Sabino da. Eu me preparei desde pequena para ser professora: em cena a professora e escritora Sandra Maria Bianchini Caixeta. In: Anais do III Encontro de História da Educação do Centro-Oeste. Catalão (GO), 2015, p. [1-]-[17-].

GRATIVOL, Samara; FERREIRA, Eliana Maria. Práticas pedagógicas para a pequena infância em Dourados/Ms: a escola serviço de educação integral (1980-1995). In: Anais do IV Encontro de História da Educação do Centro-Oeste. Campo Grande (MS), 2017, p. [1-]-[15-].

KOSSOY, Boris. Fotografia \& História. São Paulo: Ateliê Editorial, 2014.

LE GOFF, Jacques. História e Memória. Campinas, SP: Editora da UNICAMP, 1992.

LEITE, Mirian Moreira. Retratos da família: imagem paradigmática no passado e no presente. In: SAMAIN, E. (Org.). O Fotografo. São Paulo, SP: Hucitec, 1998.

LUIZ, Marilda Cabreira Leão; SANTOS, Reinaldo dos. As imagens fotográficas como fonte de pesquisa na história da educação. In: Anais do I Encontro de História da Educação do Centro-Oeste. Cuiabá (MT), 2011, p. [1-]-[07-].

MARQUES, Jackson James. Relações de gênero e livro didático de história: uma abordagem possível? Anais do II Encontro de História da Educação do Centro-Oeste. Dourados (MS), 2013, p. [1-]-[12-].

MAUAD, Ana Maria. Através da imagem: fotografia e história interfaces. Tempo, Rio de Janeiro, v. 1, n. 2, dez. 1996, p. 73-98.

MAUAD, Ana Maria. Sob o signo da imagem: a produção da fotografia e o controle dos códigos de representação social pela classe dominante no Rio de janeiro, na primeira metade do século XX. Niterói-RJ, Programa de Pós-Graduação em História Social- UFF. Tese de Doutorado, 2v. 1990. 
PESSANHA, Eurize Caldas. Escrita da História da Educação no Centro-Oeste: situação atual e perspectivas. Poíesis Pedagógica, [S.1.], v. 14, n. 1, p. 12-31, jan. 2017. ISSN 2178-4442. Disponível em: <https://www.revistas.ufg.br/poiesis/article/view/45049>. Acesso em: 21 abr. 2018. <doi:https://doi.org/10.5216/rpp.v14i1.45049>.

SÁ, Elizabeth Figueiredo de; FURTADO, Alessandra Cristina; FILHO, Wolney Honório. Memória dos Encontros de História da Educação no Centro Oeste: o que fizemos e o que podemos fazer. Poíesis Pedagógica, [S.1.], v. 14, n. 1, p. 12-31, jan. 2017. ISSN 2178-4442. Disponível em: <https://www.revistas.ufg.br/poiesis/article/view/45049>. Acesso em: $21 \mathrm{abr}$. 2018. <doi:https://doi.org/10.5216/rpp.v14i1.45049>.

SANTINI, Poliana Gianello. O arquivo escolar enquanto fonte para a História da Educação: o caso do arquivo da E. E. Dom Bosco e a história da formação de professores em Dourados/MS. In: Anais do I Encontro de História da Educação do Centro-Oeste. Cuiabá (MT), 2011, p. [1-]-[08-].

SANTOS, Alessandra de Oliveira; LEITE, Joao Victor Nunes; VIANA, Veronica Pereira. Pesquisas em História da Educação: problematização e alargamento do uso das fontes. In: Anais do III Encontro de História da Educação do Centro-Oeste. Catalão (GO), 2015, p. [1-][13-].

SCUDDER, Priscila de Oliveira Xavier; MONTEIRO, Silas Borges. Pomeri: uma escola por trás dos muros. In: Anais do I Encontro de História da Educação do Centro-Oeste. Cuiabá (MT), 2011, p. [1-]-[06-].

SILVA, Maria Aparecida Alves; LEÃO, Jeanne Mesquita de Paula; CAMARGO, Kênia Guimarães Furquim. Instituições escolares: os fundamentos teóricos e a interpretação das fontes. In: Anais do II Encontro de História da Educação do Centro-Oeste. Dourados (MS), 2013, p. [1-]-[09-].

SOUZA, Fernando dos Anjos. A participação dos militares na escolarização da fronteira Brasil - Paraguai (1945-1983). In: Anais do I Encontro de História da Educação do CentroOeste. Cuiabá (MT), 2011, p. [1-]-[08-].

SOUZA, Rosa Fátima. Fotografias escolares: a leitura de imagens na história da escola primária. In: Educar, Curitiba, n.18, p.75-101. 2001. Editora da UFPR.

VASCONCELOS, Maria Paula. O Museu da Educação do Distrito Federal e o florescimento de uma cultura de memória educacional. In: Anais do II Encontro de História da Educação do Centro-Oeste. Dourados (MS), 2013, p. [1-]-[16-].

XAVIER, Libania. A História da Educação na região Centro-Oeste: temas, abordagens teóricas e fontes. Poíesis Pedagógica, [S.1.], v. 14, n. 1, p. 12-31, jan. 2017. ISSN 2178-4442. Disponível em: <https://www.revistas.ufg.br/poiesis/article/view/45049>. Acesso em: 21 abr. 2018. doi:<https://doi.org/10.5216/rpp.v14i1.45049>.

Recebido em: 15 de março/2018

Aceito em: 20 de julho/2018 